\title{
Associations Between Defense Styles, Approaches to Learning, and Achievement Among University Students
}

\author{
Evangelia Karagiannopoulou ${ }^{1 *}$, Fotios S. Milienos ${ }^{1}$ and Vasileios Athanasopoulos ${ }^{2}$ \\ ${ }^{1}$ University of loannina, loannina, Greece, ${ }^{2}$ University of Nicosia, Nicosia, Cyprus
}

The present study explores associations between defense styles, approaches to learning, students' preferences for different types of courses/teaching and achievement. The psychometric properties of the Defense Style Questionnaire (DSQ-40), used for assessing students' defense styles, are also explored. Participants in this study were undergraduates $(N=425)$ studying in a social science department. The Approaches and Study Skills Inventory for Students (ASSIST) is used for exploring students' approaches to learning, while Grade Point Average (GPA) measured students' academic achievement. The study suggests the contribution of defense styles to the Student Learning Research; it reports a mature and an immature learning pattern. Deep and strategic approaches to

OPEN ACCESS

Edited by:

Jesus de la Fuente, University of Almería, Spain

Reviewed by: Jesús Nicasio García Sánchez, Universidad de León, Spain

Adelinda Araujo Candeias, Universidade de Évora, Portugal

*Correspondence:

Evangelia Karagiannopoulou ekaragia@cc.uoi.gr

Specialty section:

This article was submitted to Educational Psychology, a section of the journal Frontiers in Education

Received: 13 February 2018 Accepted: 15 June 2018

Published: 30 August 2018

Citation:

Karagiannopoulou E, Milienos FS and Athanasopoulos V (2018) Associations Between Defense Styles,

Approaches to Learning, and Achievement Among University

Students. Front. Educ. 3:53

doi: 10.3389/feduc.2018.00053 learning, preferences for classes that support understanding and GPA are associated with a mature defense style, whereas surface approach and preferences for classes that transmit information are associated with immature, image-distorting and neurotic defense styles. Defense styles as well as preferences for different courses appear to act as antecedents of approaches to learning; approaches mediate the effect of defenses and preferences on achievement although defenses have only a small impact. The study also suggests a four factor structure of the DSQ-40 in undergraduates. The findings are discussed in the context of the recent literature.

Keywords: defense styles, approaches to learning, preferences for courses, achievement (GPA), university students, exploratory and confirmatory factor analysis, path analysis

\section{INTRODUCTION}

The present study explores the contribution of defense styles to our understanding of students' approaches to learning. It contributes to the recent research interest in emotions (Trigwell et al., 2012) and adaptive and maladaptive dimensions involved in learning (Niculescu et al., 2015) that have a further effect on achievement. Defense styles, as unintentional coping mechanisms (a presage factor), may protect students from stress. This may result from any learning situation (Öhrstedt and Lindfors, 2018) and be associated with particular approaches to learning, depending on adaptive and maladaptive elements underlying the experience. Such a suggestion may have further implications on interventions in higher education aiming to enhance students learning taking account of their psychological maturity.

The deep, strategic (organized effort) and surface approaches represent adaptive and maladaptive studying and learning behaviors to the extent they relate to quality of learning in a positive and negative way, respectively (Entwistle, 2018). Besides, Bond (2004) suggests that 
defense mechanisms are ranked on a developmental continuum from maladaptive to adaptive with immature and mature defenses to appear in the two ends.

\section{Research in Approaches to Learning}

The educational literature discusses three major approaches: deep, surface and strategic (Entwistle et al., 2001). The central idea is the distinction between deep and surface approaches to learning (Marton and Säljö, 1976), which differentiates the students' intentions and the learning processes used to fulfill those intentions (Marton, 1975; Marton et al., 1984). A deep approach is adopted by students seeking meaning in order to understand for themselves (Trigwell and Prosser, 1991) and is associated with an intention to comprehend, to engage in active conceptual analysis while it generally results in a deep level of understanding (Entwistle et al., 2001). Students differ in how strategic they are in adapting their learning to the perceived exam requirements, by using well-organized study methods and using well-directed effort (Asikainen et al., 2014; Entwistle, 2018). This dimension combined with the deep approach correlates significantly with students' ratings of their academic progress when based on inventory scales (Entwistle, 2018). Students adopting strategic approaches draw on deep or surface learning processes differentially, depending on their perceptions of the "pay-off" in terms of grades, and also what they believe to be required in exams. Students adopting a surface approach attempt to rote and subsequently reproduce learned material in an effort to complete the task with little personal engagement while routine unreflective memorization and procedural problem solving are related strategies inevitably resulting in restricted conceptual understanding (Entwistle et al., 2001).

In the context of this research tradition (Students Approaches to Learning, SAL), students' preferences for particular courses were explored as a predictor of approaches (Baeten et al., 2010), suggesting that they may affect students' learning and, in turn, their academic performance (Entwistle, 2018). A preference for teaching methods that support understanding was positively correlated with a deep approach, whereas a preference for teaching methods that transmit information was positively correlated with surface approach (Byrne et al., 2004; Entwistle, 2009, 2018). Chamorro-Premuzic et al. (2007) described a deep approach being positively related and a surface approach being negatively related to preferences for interactive teaching methods (equivalent to courses that support understanding). Relevant research further indicated that less preferred courses are associated with a more surface approach to learning (Kember et al., 2008).

Also, approaches to learning have been found to have an effect on achievement although the findings are inconsistent (Herrmann et al., 2017). Deep, strategic and surface approaches have been positively and negatively associated, respectively, with academic achievement and study success (Richardson et al., 2012; Haarala-Muhonen et al., 2017; Herrmann et al., 2017; Entwistle, 2018). However, associations appear consistently weak. Moreover, some studies have indicated that a deep approach to learning is unrelated to academic achievement (Karagiannopoulou and Milienos, 2015; Herrmann et al., 2017). The most consistent positive association is between academic achievement and the strategic approach/organized study (Duff, 2003; Diseth et al., 2010; Rytkönen et al., 2012; Karagiannopoulou and Milienos, 2013, 2015; Asikainen et al., 2014).

In the context of students' learning, a range of studies suggests student factors (e.g., motivation, self-efficacy etc.) that are seen to function as presage factors influencing learning and achievement (Gijbels et al., 2013; Putwain et al., 2013; Postareff et al., 2014; Kyndt et al., 2018). Some studies suggest personality traits involving emotional stability namely openness, low neuroticism, conscientiousness and extraversion to be associated with approaches to learning (Chamorro-Premuzic et al., 2007; Von Stumm and Furnham, 2012). Besides, recent studies report connections between emotions, approaches to learning and study success in the expected directions (Postareff et al., 2017). The current research interest in defense mechanisms, an old psychoanalytic concept, draws on recent theoretical work on defenses as an implicit emotion-regulation construct (Rice and Hoffman, 2014; Sala et al., 2015), that involves automatic psychological processes of which individuals are unaware as they operate (Rice and Hoffman, 2014). In this line of thinking, defense mechanisms, as mental processes present in normal personality (Cramer, 2008, 2015a), are postulated to provide a rapid response and an automatic reaction, unintentional coping, to protect students from psychological stress, excessive anxiety or other negative emotions, resulting from learning situations.

Although defense mechanisms consist an early coping construct described by Freud, no study has related them to learning whilst some studies have explored the effect of cognitive coping strategies on approaches to learning (Sandover et al., 2015; De la Fuente et al., 2016, 2017).

\section{Ego-Defense Mechanisms}

Ego defense mechanisms are mental mechanisms that alter veridical perception-are postulated to function so as to protect the person from excessive anxiety, whether the source of that anxiety be the perception of a disturbing external event or a disruptive internal psychological state (e.g., a wish, drive, or fear) (Freud, 1966). Vaillant reports defense mechanisms as "involuntary coping mechanisms" (Vaillant, 2011). Thus, defense mechanisms are seen as being non-conscious, unintentional and trait like processes.

The expansion of evidence-based psychiatry and the research interest in defense mechanisms, in line with their inclusion in DSM (American Psychiatric Association) resulted in the conceptualization of defense styles as groups of defenses which represented empirically validated clusters of perceived defense mechanisms; the defense styles were seen as characterological differences. Defense styles were deeply influenced by Vaillant's hierarchical model (Vaillant, 1977) according to which defenses can be arranged on an immaturity-maturity ego continuum, corresponding to a continuum from maladaptive to adaptive: immature, image-distorting, neurotic, mature.

The immature style indicates participants' inability to deal with their impulses by taking constructive action on their own behalf. It is either treated as a unified entity or comprised by an Immature and an Image-distorting style. Overall, the four defense styles (DSQ-40, for latent adolescents) usually appear as follows: 
(a) The immature style comprises the defenses of projection, passive aggression, autistic-fantasy, somatization, displacement and acting out. It describes maladaptive action patterns that very often emerge in object relationships and may appear quite provocative. The individual deals with emotional conflicts by indirectly and often self-detrimentally expressing feelings toward someone or something (Ruuttu et al., 2006). (b) The Imagedistorting style comprises the defenses of denial, dissociation, splitting, isolation (rationalization) and devaluation. It is the splitting of the image of self and other into good and bad and into strong and weak. It differs from the immature style in being image-oriented rather than action-oriented, thus the individual refuses to acknowledge some aspect of reality (Ruuttu et al., 2006) (c) the Neurotic style comprises the defenses of undoing, pseudoaltruism, idealization and reaction formation. It keeps potentially threatening ideas, feelings, memories, wishes, or fears out of awareness (Vaillant, 2011). The rearranging of ideas and feelings is typical, so that a person can see him/herself as excessively kind, helpful to others and never angry (Ruuttu et al., 2006) (d) the Mature Style comprises the defenses of sublimation, humor, anticipation and suppression. It is associated with good coping. Defenses in this style are associated with a constructive type of mastery of the conflict (Bond, 1992; Hyphantis, 2010); they allow relatively more conscious awareness of feelings, ideas, and their consequences (Vaillant, 2011).

Empirical research on defenses with self-report inventories assumes that individuals can be aware of the residuals (Bond et al., 1983; Ruuttu et al., 2006). Also, individuals can be aware of derivatives of defenses. Such a premise, led to the development of questionnaires on defense styles (Bond et al., 1983). The accuracy of such self-report measures has been substantially supported by studies using both self-report instruments and observer-rating methods. Bond (2004) found significant positive correlations between the use of the DSQ maladaptive style and the ratings DMRS (Defense Mechanisms Rating Scales) (observer-rated method) of immature or action-level defenses. However, studies have raised psychometric limitations for some of the DSQ questionnaires. The DSQ- 40 is the most widely used questionnaire although its psychometric properties remain to be improved (Giovazolias et al., 2017).

\section{Links Between Defense Mechanisms and Learning- Adaptive/Maladaptive Dimensions}

Although there is a shortage of studies identifying associations between defense mechanisms and approaches, the two constructs share similarities with regard to personality, cognition and behavior. Defense mechanisms are generally considered stable dynamic patterns and relatively long-lasting personality features (Kramer, 2010; Laczkovics et al., 2018). Besides, research has indicated stability in approaches, described in terms of the students' disposition to understand (Entwistle, 2018); a range of studies has revealed that students hardly change their initial approach to learning in the course of their studies (Postareff et al., 2015; Asikainen and Gijbels, 2017). Moreover, defense mechanisms involve perceiving and processing information (cognition) and reacting differently to stressful situations (activity/actions) (Zhang, 2015). Similarly, approaches involve processing information (cognition) and reacting differently according to one's intention (activities).

Furthermore, both have endured long-term debates over adaptive/maladaptive value. The exploration of ways by which adaptive and maladaptive elements of defense styles and learning are intertwined is in line with Martin's (2007) "Motivation and Engagement Wheel" where all information on adaptive and maladaptive constructs goes together, respectively, in the formation of adaptive and maladaptive cognitive and behavioral dimensions. Elements of deep and strategic approaches, e.g., seeking meaning, interest in ideas, monitoring effectiveness and time management can be seen to correspond respectively to mastery-orientation and self-efficacy and also to persistence and planning in Martin's model. Moreover, all information on maladaptive constructs goes together: surface elements like (a) lack of purpose, syllabus boundness and (b) fear of failure, seem to correspond to uncertain control and anxiety respectively (maladaptive cognitive dimensions, Martin's model). Concerning the defense styles, the mature defense style and the less mature/immature defense styles can be seen to correspond to adaptive and maladaptive cognitive and behavioral dimensions in Martin's model, in terms of competence and self-confidence and also in terms of weakness in cognitive functioning, irresponsibility, unclear "fuzzy" thinking and anxiety, involved in the mature and immature defense styles, respectively (Cramer and Tracy, 2005).

In the strand of research on dimensions that impact on learning, adaptive and impeding cognitions (including anxiety, failure avoidance, uncertain control) and behaviors have recently been explored (Niculescu et al., 2015) as distal antecedents (presage factors) that have an effect on learningrelated emotions and students' achievement; academic control followed by learning hopelessness were the main predictors of course performance. Besides, research has indicated that positive associations between adaptive (e.g., problem-focused, actionemotion style competitiveness-hardworking), and maladaptive ways of coping with a deep approach to learning (Sandover et al., 2015), academic performance (De la Fuente and CardelleElawar, 2009) and a surface approach (De la Fuente et al., 2016), respectively. Also, negative associations have been found between maladaptive ways of coping (e.g., self-handicapping, procrastination) (Lindblom-Ylänne et al., 2015), deep approaches and exam grade (De la Fuente et al., 2017).

Single research studies reported positive links between emotional stability (low neuroticism), openness and conscientiousness, and a deep approach as well as between conscientiousness and a strategic approach. Also, emotional stability and openness negatively predicted a surface approach (Burton et al., 2009). Besides, achieving learning (equivalent to strategic approach) was found to be predicted by broad personality traits, namely openness to experience, extraversion and conscientiousness (Duff et al., 2004; Von Stumm and Furnham, 2012). In the same strand of research, preferences for interactive teaching (equivalent to courses that support understanding) (Chamorro-Premuzic et al., 2007), as a predictive variable, appeared to be associated with personality traits of 
emotional stability and agreeableness, and a deep approach to learning.

The recent research interest in defense mechanisms is depicted in Zhang and Sternberg (2006) and Zhang (2015) work on associations between defense styles and thinking styles. She has taken a cognitive perspective to explore the value of thinking styles and defense mechanisms; thinking styles significantly predicted defense mechanisms largely in the expected directions. Type I, adaptive thinking styles, that include creativity generating and higher levels of cognitive complexity (Zhang and Sternberg, 2006), positively predicted defense mechanisms, widely recognized to be more adaptive (Campos et al., 2011); they also negatively predicted the three defense mechanisms that directed negative emotions. On the contrary, research proven Type II, less adaptive thinking styles, that involved a norm-confirming tendency and required lower levels of cognitive complexity, positively contributed to the variance in defenses, widely considered to be less adaptive (immature, neurotic and image-distorting defense styles). Recently, a single study suggested relations between defense styles, approaches and GPA (Karagiannopoulou et al., 2015) indicating that defense mechanisms predicted in the expected direction approaches to learning. More specifically, deep and strategic approaches to learning were predicted by a mature defense style whereas an immature defense style predicted surface approach.

To our knowledge, the specific functional aspects of defense mechanisms in relation to approaches to learning, to protect the self from stress resulting from learning situations, and their role in achievement have not been tested among university student population although there is increasing research interest in academic emotions.

The main objective of the study is to explore the contribution of Defense Styles, as involuntary coping mechanisms, to the SAL tradition. In particular, the study explores (a) whether adaptive and maladaptive defense styles and approaches (along with GPA) are consistently associated and (b) what are the paths associating defense styles, course preferences, approaches and achievement (as the outcome variable).

The above research questions have led to the following hypotheses.

- H1. A mature defense style is positively associated with deep and strategic approaches, preferences for courses supporting understanding and GPA, comprising an adaptive learning pattern;

- H2. Neurotic, Immature and Image distorting defense styles are positively associated with a surface approach and preference for courses transmitting information comprising a maladaptive learning pattern;

- H3. Approaches to learning mediate the effect of defense styles and preferences on GPA;

- H4. Defense styles and preferences mediate the effect of approaches on GPA.

\section{Aims and Relevance}

The main aim of the present study is to explore, through the use of SEM, two models that help to explain the relationships among defense styles, preferences for courses, approaches to learning, and achievement. In the following models defenses and preferences are explored at the same stage as student factors that can be seen as both stable as well as state constructs associated with approaches. Although few studies have indicated the influence of personality traits on preferences, the results are not confirmed for non-interactive teaching (equivalent to courses transmitting information) (Chamorro-Premuzic et al., 2007). Thus our models comprise three levels: defense styles and preferences, approaches to learning and GPA.

The first model explores the research hypothesis H3. It is the most commonly attributed explanation where approaches to learning mediate the effect of students' defense styles and preferences for particular courses on achievement. In this model, approaches to learning appear as a process factor related to defense styles and preferences for particular courses (Baeten et al., 2010). It draws on studies reporting students' preferences for particular courses and personality dimensions involving emotional stability-instability, as presage factors that predict approaches to learning.

The second model explores the second possibility, research hypothesis $\mathrm{H} 4$, with approaches to learning appearing as a presage factor and defense styles and preferences for particular courses being the process factors that mediate the effect of approaches on achievement. We assume that students have developed a particular approach to learning by the time they enter the university which hardly changes in the course of their study (Asikainen et al., 2014; Asikainen and Gijbels, 2017). Moreover, research has reported stability, described in terms of the students' disposition to understand (Entwistle and McCune, 2013; Entwistle, 2018). A habitual/stable approach to learning may evoke stress depending on whether consonant or dissonant with the teaching and the relevant demands (Lindblom-Ylänne, 2003; Karagiannopoulou and Entwistle, 2013; Entwistle et al., 2015). Stress from any learning situation may in turn activate either adaptive or maladaptive defense styles in order for students to protect themselves from inordinate anxiety.

In the above two models, GPA always appears at the third stage, as product factor. Overall, the exploration of these two models is shedding light on whether students are relatively consistent in the way of learning which evokes particular defenses and preferences for courses or whether they typically vary their approach according to preferences for particular courses (an integrative component of student learning) and the use of particular defense styles to protect themselves from stress as well as testing the relation of both approaches and defense styles and preferences with GPA (learning outcome).

\section{METHODOLOGY}

\section{Participants}

A sample of 425 undergraduates (18\% men and $82 \%$ women), studying for a joint degree in a School of Philosophy that leads to three majors: philosophy, education and psychology, participated in the study (the ethics committee, University of Ioannina, Greece, 1471/175/2-2-2017). Most of the degree courses are traditional lecture-designed; tuition is free for the students. The 
average age of the sample was 20.29 years $(s d=3.09)$ and $29 \%$ of students were first year students, $32.1 \%$ second year students, $22.6 \%$ third year and $16.3 \%$ fourth (last) year students. Any student who attended the spring term classes voluntarily participated in the study (the response rate was almost 90\%); they anonymously completed printed questionnaires (pencil and paper technique) prior to lectures. The purpose of the study was communicated well in advance to the students; no personal data was included in the questionnaire, thus there was no need for students to complete a consent form (consent was obtained by virtue of survey completion). Selection criteria for the sample included: (a) studying for first time at degree level (b) no adult students were included in the study (c) senior students should have declared psychology major (d) no delayed students were included in the study.

\section{Instruments}

\section{Approaches and Study Skills Inventory for Students (ASSIST)}

The ASSIST is a revised version of the Approaches to Studying Inventory originally developed by Entwistle and Ramsden (1983). It has been acknowledged as the most robust instrument for measuring approaches to learning (Richardson, 2006) and has been used in a large number of studies across many countries and languages (Diseth, 2001; Karagiannopoulou and Christodoulides, 2009; Valadas et al., 2010; Anderson et al., 2011).

The ASSIST consists of three main sections measuring conceptions of learning, approaches to learning and preferences for different types of course and teaching, followed by a single question concerning the self-evaluation of achievement. All of the sections except for the section measuring conceptions of learning were used in the present study. The ASSIST section on approaches to learning consists of 52 items in a 5-point Likert scale, forming three main scales of deep (i.e., I usually set out to understand for myself the meaning of what we have to learn), strategic (i.e., I organize my study time carefully to make the best use of it), and surface approach (i.e., Often I find myself wondering whether the work I am doing here is really worthwhile), consisting of four, five and four subscales, respectively. The ASSIST section on preferences for different types of course and teaching consists of 8 items producing two 4 -item subscales that involve support understanding (i.e., I prefer exams which allow me to show that I've thought about the course material for myself) and transmit information (i.e., I prefer lecturers who tell us exactly what to put down in our notes). The validity of the ASSIST (section of approaches to learning) in our specific university setting has recently been explored (Karagiannopoulou and Milienos, 2013, 2015) with the analysis carried out at subscale level producing the expected threefactor structure (corresponding to strategic, deep and surface approaches); internal consistency of the scale was found to be satisfactory.

\section{The Defense Style Questionnaire (DSQ-40)}

The DSQ-40 (Andrews et al., 1993) was based on the Defense Style Questionnaire (DSQ), a self-report measure originally created by Bond et al. (1983). The latter was revised by Bond and Vaillant (1986) and later modified by Andrews et al. (1989).
The DSQ-40 constitutes a short version of the last modified version of DSQ. It comprises 40 items in a 9-point Likert scale forming three main scales of mature (i.e., I'm able to keep a problem out of my mind until I have time to deal with it), immature (i.e., People tend to mistreat me) and neurotic (i.e., After I fight for my rights, tend to apologize for my assertiveness) defense styles consisting of four, twelve and four 2-item subscales respectively that correspond to twenty defense mechanisms in total; the mature defense style comprises the defenses of sublimation, humor, anticipation and suppression; the immature defense style comprises the defenses of projection, passive aggression, acting out, isolation, devaluation, autistic fantasy, denial, displacement, dissociation, splitting, rationalization and somatization; the neurotic defense style comprises the defenses of undoing, pseudo-altruism, idealization and reaction formation.

The DSQ, in its various versions, has been widely used in studies across the countries (Andrews et al., 1989, 1993; Spinhoven et al., 1995; Ruuttu et al., 2006; Hyphantis, 2010), while it has been found appropriate to differentiate between normal controls and, among others, patients with anxiety, childabusing parents (Andrews et al., 1993), subjects with mood disorders (Ruuttu et al., 2006) and subjects with personality disorders (Schauenburg et al., 2007). However, studies have raised psychometric limitations suggesting further exploration of the psychometric characteristics of the questionnaire, using a variety of samples (Wilkinson and Ritchie, 2015). On the contrary, studies have been generally reported DSQ to be a substantially valid measure (Watson, 2002; Ruuttu et al., 2006; Carvalho et al., 2013) with reasonable sufficient psychometric properties. Factor analysis studies of the DSQ-40 have yielded three defense styles, namely mature, immature and neurotic defense styles (Andrews et al., 1993; Schauenburg et al., 2007) or, occasionally, four comparable factors which give acceptable but not high reliability coefficients (Ruuttu et al., 2006; Giovazolias et al., 2017).

\section{Achievement}

Students' achievement was measured by a self-report question in which students were asked to give the GPA on the basis of the modules they had already attended. GPA, as a measure of academic performance, is widely recognized and is one of the most studied variables in education and educational psychology (Kuncel et al., 2005). It has been used with many studies on personality and academic achievement, as a criterion variable (Wagerman and Funder, 2007; Karagiannopoulou and Milienos, 2013, 2015). However, limitations of the GPA, as a study variable, have been reported as the accuracy of students' self reported grades may vary with actual student performance (Kuncel et al., 2005; Dickinson and Adelson, 2016). Research results suggests that self reported grades are reasonably good reflections of actual grades with high ability and good grade point average (Kuncel et al., 2005), while this is not the case for low GPA students. Moreover, in a previous study with students of the same department we identified high correlations between selfreported GPA and students' evaluation of their achievement, on the basis of the grades supported by the official records (Karagiannopoulou and Milienos, 2013, 2015). 


\section{Adaptation Process}

The DSQ-40 was translated into Greek following the International Test Commission (ITC) guidelines for test adaptation (Hambleton, 2001) and the Beaton et al. (2000) suggestions. Items of the original version were translated into Greek by two bilingual speakers and then another two bilingual speakers back-translated the scale to English. After the back translations minor translation discrepancies were found and minor vocabulary adaptations were made. Also, each item of the scale was examined by a panel of researchers/experts who were familiar with the literature and the research area, in order to establish the face validity, the content and the cultural appropriateness of the questionnaire. Any change was based on their suggestions at this point. The translated questionnaire was pilot tested for a field test to a small sample of undergraduates $(N=20)$ in the target population who examined it for appropriateness of the questions, clarity, language stability and wording. The items that did not appear appropriate for the particular sample were adjusted according to the student's suggestions.

\section{Data Analysis}

Confirmatory factor analysis was used for assessing the psychometric properties of the DSQ, along with the computation of Cronbach's alpha, Average Variance Extracted, composite reliability and coefficient omega (McDonald, 1999). To identify differences in approaches to learning and defense styles, across the 4 years of study, the techniques of ANOVA were used. The Pearson correlations coefficients among defense styles, approaches to learning, preferences for different types of courses/teaching and GPA were also computed. Furthermore, for studying the latent structure among ASSIST, DSQ-40 (at subscale level), preferences for different types of course and teaching, and GPA, the sample was randomly divided into two equal parts; an exploratory factor analysis was contacted in the first half of our sample and the derived factor structure was verified on the other half of our sample by confirmatory factor analysis. Finally, based on the techniques of Path Analysis (using the item parceling approach) two models which further explore the relationship among ASSIST, DSQ-40 and GPA, were studied. The analysis of the dataset was performed using SPSS23.0 and AMOS 16.

\section{RESULTS}

Confirmatory factor analysis was used for the evaluation of the psychometric properties of the DSQ-40; specifically, the fit of the model depicted in Figure $\mathbf{1}$ is assessed by the following tests and indices: chi-square $=326.02(d f=150, p<0.001)$, comparative fit index $(\mathrm{CFI})=0.85$, goodness-of-fit index $(\mathrm{GFI})=0.93$, adjusted goodness-of-fit index (AGFI) $=0.90$, normed fit index $(\mathrm{NFI})=0.76$, Tucker-Lewis index $(\mathrm{TLI})=0.81$, root mean square error approximation (RMSEA) $=0.053$ (with $90 \%$ confidence interval from 0.045 to 0.060 ) and standardized root mean square residual $(\mathrm{SRMR})=0.063$. Note that (Figure 1) some covariances between residual/error terms associated with indicators of immature and image-distorting factors, have been estimated by the data and not set equal to zero; this can be readily explained by the nature of these two factors. Since most of the indices are found in acceptable range of values (i.e., RMSEA and SRMR are quite small, while AGFI, GFI, and CFI take on large enough values) it can be said that the latent structure of the DSQ-40 has partially been verified. In line with previous studies reporting psychometric weaknesses of the DSQ-40, the latent structure of the instrument should be treated with caution. Such a suggestion is also supported by the low to moderate values of Cronbach's alpha, Average Variance Extracted (AVE) (used for assessing the convergent validity of an instrument; e.g., Gefen et al., 2000), and coefficient omega (or composite reliability; McDonald, 1999); Table 1 includes all the above details from which it can be seen that (a) some of Cronbach's alpha (e.g., for mature and neurotic defense style) are of moderate level but of similar magnitude with previous studies (e.g., Ruuttu et al., 2006; Giovazolias et al., 2017), (b) some of the correlations between the four factors are larger than the respective AVE, and (c) all the values of coefficient omega are less than 0.5. According to the failure of the above indices to meet the cut off points suggested by the relevant literature, the results/calculations of the subsequent analyses should be treated with caution and discussed under the weak psychometric properties of DSQ- 40 .

The Pearson correlations coefficients among the four defense styles, the three approaches to learning, preferences for different types of courses/teaching and achievement can also be found in Table 1. It is of interest to mention that a mature defense style was positively correlated with a deep approach, a strategic approach, students' preference for classes that support understanding and GPA, where as negatively correlated with a surface (apathetic) approach. The neurotic defense style was positively correlated with a surface approach and students' preference for classes that transmit information. The immature defense style was positively correlated with a surface approach and negatively correlated with a deep approach as well as with a preference for classes that support understanding. There was no statistically significant correlation between image-distorting defense style and other variables.

The results from ANOVA did not indicate any significant difference in defense mechanisms across the years of study (neurotic with $p=0.533$; immature with $p=0.112$; imagedistorting with $p=0.177$ ), except the mature defense style ( $p$ $=0.045$ ); specifically, it seems that the last year students score higher on mature defense style (mean $=5.69$ ) than the first year students (mean $=5.23$ ). The results are similar for the ASSIST subscales in which no significant differences exist (deep with $p=$ 0.665 ; strategic with $p=0.242)$ except the surface approach $(p<$ $1 \%)$; the second year students score higher on surface approach (mean $=54.23$ ) than students from the fourth and third year of study (mean $=50.92$ and 50.99, respectively).

To explore the latent structure among defense styles, approaches to learning, preferences for different types of course and teaching and GPA, the sample was randomly divided into two equal parts; an exploratory factor analysis was contacted in the first half of our sample and the derived factor structure was verified on the other half of our sample by confirmatory factor analysis. Table 2 shows the results from the exploratory factor analysis. 

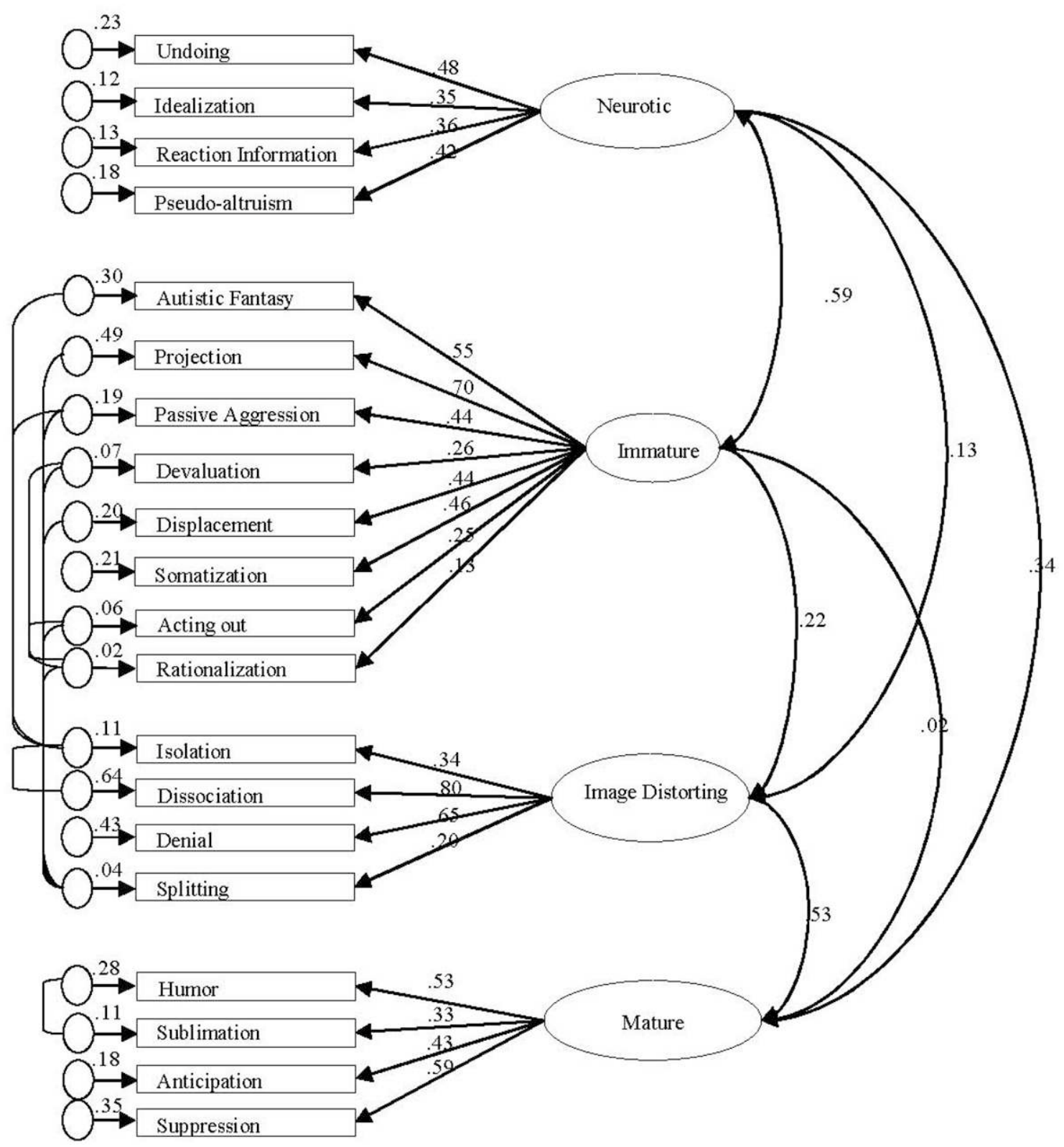

FIGURE 1 | Confirmatory Factor Analysis on DSQ-40 (standardized estimates).

Although, the 3 factors deduced by Kaiser rule explain the $55.96 \%$ of data variability, this criterion often overestimates the number of underlying factors, especially when the number of items is large (Kahn, 2006). Hence, it is necessary to consider other decision rules, as the parallel analysis which suggests the existence of 2 factors; see Table 2 where the third eigenvalue is the first eigenvalue less than the corresponding 95\% percentile of the generated eigenvalues. Furthermore, according to the structure and pattern matrix, the two factor solution is the most interpretable solution.

Now, we are going to verify the above deduced latent structure, carrying out a confirmatory factor analysis on the second half of our sample. Hence, the model in Figure 2 is assessed by the following fit indices: chi-square $=129.7(d f=$ $27, p<0.001)$, CFI $=0.90$, GFI $=.095$, AGFI $=0.90$, NFI $=0.83, \mathrm{TLI}=0.75$, RMSEA $=0.095$ (with $90 \%$ confidence interval from 0.079 to 0.111 ) and $S R M R=0.068$. Note that most of these values are found in acceptable intervals and hence, it can be said that the model adequately fits the data. However, the small correlations among image-distorting and the other variables (see Table 1) and the small effect of maladaptive pattern on image-distorting, suggest that excluding this factor from the CFA may improve the fitness of the model; indeed, this model without image-distorting gives us chi-square $=71.8(\mathrm{df}$ 
TABLE 1 | Pearson correlations among defense styles, approaches to learning, preferences for different types of course/teaching and GPA; Cronbach's alpha ( $\alpha$ ), Average Variance Extracted (AVE), and coefficient omega ( $\omega)$, in parentheses.

\begin{tabular}{|c|c|c|c|c|c|c|}
\hline & \multicolumn{3}{|c|}{ Approaches to Learning } & \multirow{2}{*}{$\begin{array}{l}\text { Supporting } \\
\text { understanding }\end{array}$} & \multirow{2}{*}{$\begin{array}{l}\text { Transmitting } \\
\text { information }\end{array}$} & \multirow[t]{2}{*}{ GPA } \\
\hline & $\begin{array}{c}\text { Deep } \\
(\alpha=0.850)\end{array}$ & $\begin{array}{l}\text { Strategic } \\
(\alpha=0.768)\end{array}$ & $\begin{array}{l}\text { Surface } \\
(\alpha=0.593)\end{array}$ & & & \\
\hline \multicolumn{7}{|l|}{ DEFENSE STYLE } \\
\hline $\begin{array}{l}\text { Mature } \\
(\alpha=0.537, \operatorname{AVE}=0.30, \omega=0.26)\end{array}$ & $0.260^{\star \star}$ & $0.134^{\star \star}$ & $-0.135^{\star \star}$ & $0.176^{\star \star}$ & -0.038 & $0.160^{\star \star}$ \\
\hline $\begin{array}{l}\text { Neurotic } \\
(\alpha=0.541, \text { AVE }=0.16, \omega=0.16)\end{array}$ & 0.086 & 0.055 & $0.213^{\star \star}$ & 0.076 & $0.151^{\star \star}$ & -0.006 \\
\hline $\begin{array}{l}\text { Immature } \\
(\alpha=0.738, \text { AVE }=0.19, \omega=0.17)\end{array}$ & -0.069 & -0.003 & $0.345^{\star \star}$ & $-0.131^{\star \star}$ & $0.115^{\star}$ & -0.052 \\
\hline $\begin{array}{l}\text { Image-distorting } \\
(\alpha=0.619, \mathrm{AVE}=0.23, \omega=0.22)\end{array}$ & -0.087 & 0.034 & 0.044 & -0.051 & 0.017 & 0.020 \\
\hline
\end{tabular}

${ }^{\star} p<0.05,{ }^{* \star} p<0.01$.

TABLE 2 | Exploratory Factor Analysis (on the correlation matrix; Principal Component/Promax rotation), parallel analysis and correlations among factors.

\begin{tabular}{|c|c|c|c|c|}
\hline & \multirow{2}{*}{\multicolumn{2}{|c|}{$\begin{array}{c}\text { Pattern matrix } \\
\text { Component }\end{array}$}} & \multirow{2}{*}{\multicolumn{2}{|c|}{$\begin{array}{c}\text { Structure matrix } \\
\text { Component }\end{array}$}} \\
\hline & & & & \\
\hline & 1 & 2 & 1 & 2 \\
\hline \multicolumn{5}{|c|}{ EXPLORATORY FACTOR ANALYSIS } \\
\hline GPA & 0.563 & & 0.570 & \\
\hline Mature & 0.519 & & 0.475 & \\
\hline Strategic & 0.720 & & 0.697 & \\
\hline Supporting understanding & 0.679 & & 0.715 & \\
\hline Deep & 0.817 & & 0.801 & \\
\hline Immature & & 0.680 & & 0.660 \\
\hline Image-distorting & & 0.541 & & 0.495 \\
\hline Neurotic & & 0.571 & & 0.528 \\
\hline Transmitting information & & 0.616 & & 0.662 \\
\hline Surface & & 0.646 & & 0.699 \\
\hline Eigenvalues & Real & Random (95\%) & $\%$ variance & \\
\hline \multicolumn{5}{|l|}{ PARALLEL ANALYSIS } \\
\hline 1 & 2.598 & 1.510 & 22.98 & \\
\hline 2 & 1.754 & 1.364 & 43.52 & \\
\hline 3 & 1.244 & 1.255 & 55.96 & \\
\hline \multicolumn{5}{|c|}{ COMPONENT CORRELATION MATRIX } \\
\hline 1 & 1 & -0.214 & & \\
\hline 2 & -0.214 & 1 & & \\
\hline
\end{tabular}

Loadings below 0.35 are not displayed.

$=21, p<0.001), \mathrm{CFI}=0.92, \mathrm{GFI}=0.97, \mathrm{AGFI}=0.93, \mathrm{NFI}$ $=0.89, \mathrm{TLI}=0.85$, RMSEA $=0.076$ (with $90 \%$ confidence interval from 0.057 to 0.095 ) and SRMR $=0.058$. The results indicate the existence of associations among defense styles, approaches to learning, preferences for different types of courses and GPA.

Here, we are going to test two different three-stage models, to explore which of them provides the best statistical fit to our data. In the first model (Model 1), the four factors of DSQ40 (i.e., neurotic, immature, image-distorting and mature) along with supporting understanding and transmitting information, are placed before the three factors of ASSIST (i.e., deep, strategic and surface), whereas in the second model (Model 2), the three factors of ASSIST are found before the four factors of DSQ40 and supporting understanding and transmitting information; in each of these two models, GPA is at the last stage (outcome variable). Every variable in the model is directly affected only by the variables of the previous stage; the error variables (on the same stage) and all independent variables of the model are assumed potentially correlated (the estimation of the model parameters is carried out by the asymptotically distribution-free method).

The fit of models is assessed by the tests and descriptive fit indices found in Table 3; obviously, Model 1 (the model with the DSQ-40, supporting understanding and transmitting information at the first stage; see Figure 3) reveals a better fit than the second model since it has the largest values for GFI, AGFI, CFI, and the smallest for RMSEA, SRMR, and AIC. Note also that the null hypothesis that Model 1 fits to the data equally well with the full model is not rejected at a significance level of $0.01(p=0.034)$. At the same time, the indices of Model 1 meet most of the requirements for an acceptable fit (i.e., RMSEA and SRMR are small enough, while AGFI, GFI, and are all larger than 0.90).

Table 4 includes the parameter estimates (un-standardized and standardized estimates) of Model 1 and the corresponding $p$-values. It can be seen that:

a) Strategic approach has the greatest significant effect on GPA; Deep approach has also a positive effect on GPA, however its $p$-value is just over the 0.05 significance level;

b) the variables support understanding and transmit information have also a statistically significant positive effect on strategic;

c) the factors mature and image-distorting have a positive and negative effect on deep approach; support understanding has the greatest positive effect on deep approach;

d) the factors mature and immature have a negative and positive effect on surface approach; transmit information has the greatest positive effect on surface approach.

Table 5 contains the direct and indirect effects of the exogenous (independent) variables on the endogenous (dependent) ones, along with the implied correlations from the model and the 


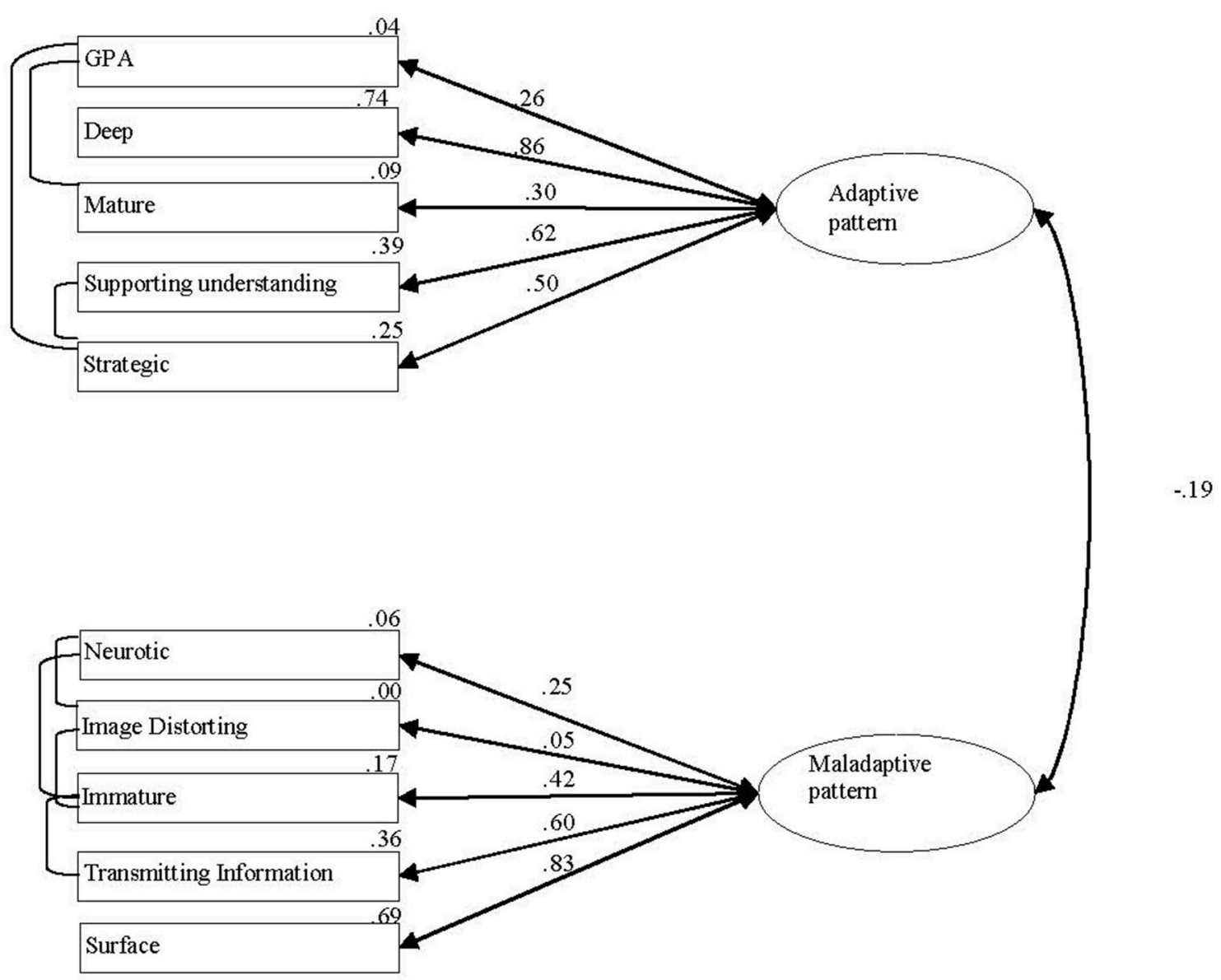

FIGURE 2 | ConfirmatoryFactor Analysis (standardized estimates) on the derived latent structure by the first half of our sample provided in Table 2.

TABLE 3 | The fit indices of the two three-stage models.

Model $^{*}$

1

2
Chi-square

$13.669(\mathrm{df}=06, p=0.03)$

$41.767(\mathrm{df}=05, p<0.01)$

\section{GFI}

0.992

0.976
AGFI

0.927

0.731

.927
.731

0.971
0.912

0.982
0.915

0.915

"Model 1: DSQ-40, supporting understanding and transmitting information at the first stage, ASSIST at the second and GPA at the third stage. Model 2: ASSIST at the first stage, $D S Q-40$, supporting understanding and transmitting information at the second stage, and GPA at the third stage.

non-causal effects. It has to be noted that only mature and support understanding have significant (positive) indirect effects on GPA, which is further combined by the significant (positive) direct effect of strategic approach on GPA. The only significant correlation among the error variables is that between error 1 and 2 which is equal to 0.376 (with $p<0.001$ ); this means that unknown common causes (not included in the model) exist between deep and strategic approach. The variances of the error variables are all statistically significant, and therefore it may be said that there are other variables, not included in the model, which have a significant contribution to the variability of the dependent variables. The decomposition of the two significant indirect effects can be found in Table 6; it can be seen that the indirect effects of mature and GPA are mainly due to their influence on deep and strategic approach.

\section{DISCUSSION}

The study suggests that defense styles can be considered to contribute to student learning. It indicates a mature/adaptive and an immature/maladaptive learning pattern. The effect of defense styles on achievement is mediated by approaches to learning. The psychometric properties of the DSQ-40 were also examined. In line with previous findings, the study suggests a four-factor solution discriminating between immature, imagedistorting, neurotic and mature defense styles (Ruuttu et al., 2006; Giovazolias et al., 2017). This is inconsistent with the 


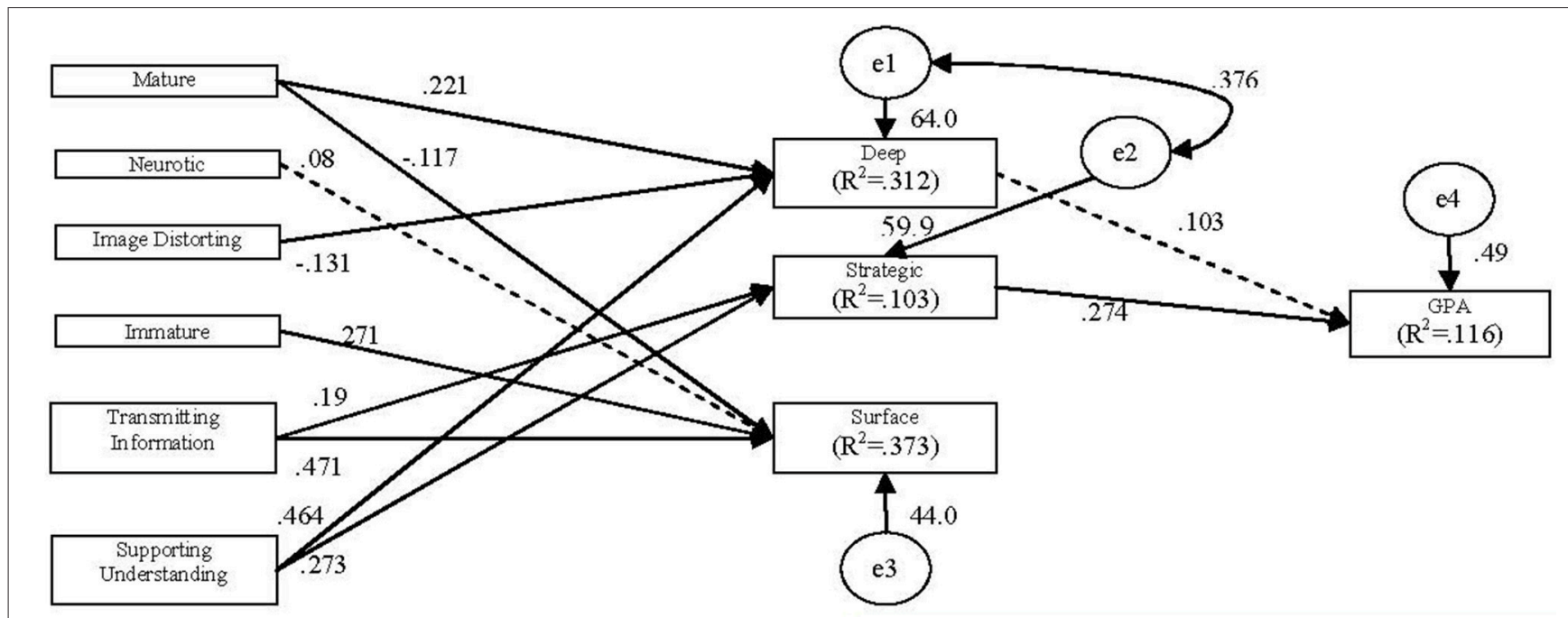

FIGURE 3 | The model with the best fit on our data among the two studied three-stage models (see also Table 3; the covariances among independent and error variables are not mentioned, for typographical convenience); the standardized path coefficients, correlations among the error variables and their variances (only the statistical significant are included) are included.

original study (three-factor solution, Andrews et al., 1993). The low to moderate alphas of mature and neurotic defenses styles in comparison to immature and image-distorting styles are consistent with previous studies (Seaton and Beaumont, 2011; Giovazolias et al., 2017) and possibly indicate the small number of items comprising these two styles.

\section{Defense Styles, Approaches to Learning and Achievement}

The study reveals associations between defense styles and approaches to learning indicating a mature and an immature learning pattern (Martin, 2007; Niculescu et al., 2015). Psychological maturity, and immaturity depicted in the increased use of adaptive and maladaptive defense styles are associated with adaptive and maladaptive learning activities that involve personal engagement leading to the development of personal understanding and maladaptive learning activities leading to or the completion of the task with little personal engagement, respectively. In particular, a deep approach, a strategic approach, preferences for courses that support understanding and GPA are associated with constructive ways of mastering conflicts- a mature defense style. Also, a surface approach and preferences for courses that transmit information are associated with maladaptive non-conscious ways of reducing anxiety-neurotic, immature and imagedistorting defense styles. The findings are in line with previous studies indicating relations between adaptive and maladaptive elements of behavior and cognition with leaning approaches in the expected directions. In particular, emotional stability and instability(Chamorro-Premuzic et al., 2007), adaptive and maladaptive ways of coping (Sandover et al., 2015) and positive and negative emotions (Trigwell et al., 2012;
Postareff et al., 2017) have been related to a deep and a surface approach.

The two patterns do not appear independent but rather low negatively correlated. This may reflect the increasing use of mature defenses and the decreasing use of immature defenses with the age. It may also reflect the non-clinical sample of the study; individuals with fewer symptoms of mental illness report a larger repertoire and a more flexible utilization of defenses (Cramer, 2015b). With regard to approaches to learning, this low correlation may indicate the correspondence of approaches to exam demands; research reports that strategic students draw on deep or surface learning processes differentially, depending on their perceptions of the "pay-off" in terms of grades, and also what they believe to be required in exams (Entwistle, 2018; Lindblom-Ylänne et al., 2018).

\section{The Path Model}

In support to the mature/adaptive and immature/maladaptive pattern, the path analysis indicated associations that reveal the contribution of defense styles to the SAL tradition in the expected directions. Mature defense styles affects GPA positively, through a deep and strategic indicating the mediating role of approaches between defense styles and GPA. The use of a mature defense style that has an effect on a deep and strategic approach that in turn has some effect on achievement possibly reflects an interaction between constructive ways to cope with anxiety, one's tolerance to get into grips with the meaning and higher exam scores (Chamorro-Premuzic et al., 2007).

The expected associations between defense styles and approaches support previous findings reporting links between cognitive complexity and adaptive defense mechanisms and also links between lower levels of cognitive complexity and less adaptive defense mechanisms (Zhang, 2015). A mature defense 
TABLE 4 | The un-standardized and standardized parameter estimates of the model of Figure 3.

\begin{tabular}{|c|c|c|c|c|}
\hline Effect & $\begin{array}{l}\text { Parameter } \\
\text { estimate }\end{array}$ & $\begin{array}{l}\text { Standard } \\
\text { error }\end{array}$ & $\begin{array}{l}\text { Standardized } \\
\text { estimate }\end{array}$ & $p$-value \\
\hline \multicolumn{5}{|l|}{ ON DEEP $\left(R^{2}=0.312\right)$} \\
\hline Of neurotic & 0.209 & 0.404 & 0.024 & 0.606 \\
\hline Of Image-distorting & -1.048 & 0.332 & -0.131 & 0.002 \\
\hline Of transmitting information & -0.051 & 0.130 & -0.018 & 0.696 \\
\hline \multicolumn{5}{|l|}{ ON STRATEGIC $\left(R^{2}=0.103\right)$} \\
\hline Of mature & 0.650 & 0.370 & 0.089 & 0.078 \\
\hline Of neurotic & -0.065 & 0.404 & -0.009 & 0.873 \\
\hline Of image-distorting & 0.158 & 0.331 & 0.023 & 0.634 \\
\hline Of mature & -0.884 & 0.288 & -0.117 & 0.002 \\
\hline Of neurotic & 0.616 & 0.317 & 0.080 & 0.052 \\
\hline Of image-distorting & -0.229 & 0.278 & -0.033 & 0.410 \\
\hline Of immature & 2.113 & 0.349 & 0.271 & $<0.001$ \\
\hline Of supporting understanding & -0.027 & 0.115 & -0.010 & 0.815 \\
\hline Of transmitting information & 1.146 & 0.103 & 0.471 & $<0.001$ \\
\hline \multicolumn{5}{|l|}{ ON GPA $\left(R^{2}=0.116\right)$} \\
\hline Of deep & 0.008 & 0.004 & 0.103 & 0.059 \\
\hline Of strategic & 0.025 & 0.005 & 0.274 & $<0.001$ \\
\hline Of surface & -0.007 & 0.004 & -0.073 & 0.121 \\
\hline
\end{tabular}

style has a positive and negative effect on deep and surface approaches, respectively. Besides, an image-distorting defense style has a negative effect on a deep approach. Also neurotic and immature defense styles have a positive effect on surface approach. Possibly, maladaptive defense styles depict higher levels of anxiety underlying a fear of failure (a surface element). This goes in tandem with lower confidence in one's abilities to grasp a subject matter or to perform well in exams, and make students to opt for a surface rather than deep approach, as the latter may be hindered by worries and de-focused attention. Besides, "being fast helps students to regulate stress" (ChamorroPremuzic et al., 2007).

The failure of an image-distorting defense style to have a direct effect on a surface approach while this is the case for an immature defense style possibly indicates that this association is not appropriate for a non-clinical sample; the use of such a defense style may lead to a decreasing use of an adaptive deep approach but not to an increasing use of a maladaptive surface approach. Besides, the two defense styles are of different nature. The immature style involves object relations; studentteacher relations are gradually attracting more research interest concerning their effect on students' learning (Karagiannopoulou and Entwistle, 2013; Hagenauer and Volet, 2014; Entwistle et al., 2015; Rowe et al., 2015). On the other hand, the image-distorting style involves refusal of some aspects of reality which is not often the case with non-clinical samples.
The weak correlations across the variables at the three levels of the model and the low account of variance of defense styles over approaches are in line with previous studies exploring associations between personality and approaches (e.g., Furnham and Chamorro-Premuzic, 2005; Furnham et al., 2013) and those indicating low or no correlations between a deep approach and achievement (Richardson et al., 2012; Karagiannopoulou and Milienos, 2013; Lindblom-Ylänne et al., 2018). Besides, studies exploring, by the use of path analysis, the effect of academic emotions on achievement through variables such as engagement (equivalent to a deep approach) or disengagement (equivalent to a surface approach), give low associations among the variables at different levels (Robinson et al., 2017).

In line with the relevant literature, students' preference for courses that support understanding affects GPA through deep and strategic approach. Besides, the strategic approach has a direct positive effect on GPA (Rytkönen et al., 2012; Karagiannopoulou and Milienos, 2013, 2015; Asikainen et al., 2014). The effect of students' preferences for courses that support understanding on GPA through deep and strategic approaches can be seen to be supported by positive association of this preference to mature defense style. Earlier studies indicated that a preference for interactive teaching methods (an equivalent to preferences for courses that support understanding) is associated with a combination of emotional stability (low neuroticism) and agreeableness (equivalent to the use of mature defenses) 
TABLE 5 | The sample $(r)$ and implied correlations among dependent and independent variables, and the standardized direct and indirect on dependent variables of the model of Figure $\mathbf{3}$ (along with the no-causal effect).

\begin{tabular}{|c|c|c|c|c|c|}
\hline Effect & $r$ & $\begin{array}{l}\text { Standardized } \\
\text { direct }\end{array}$ & $\begin{array}{l}\text { Standardized } \\
\text { indirect }\end{array}$ & $\begin{array}{l}\text { Implied } \\
\text { correlation }\end{array}$ & $\begin{array}{l}\text { No } \\
\text { causal }\end{array}$ \\
\hline \multicolumn{6}{|l|}{ ON DEEP } \\
\hline Of neurotic & 0.086 & 0.024 & - & 0.079 & 0.055 \\
\hline Of image-distorting & -0.087 & $-0.131^{\star \star}$ & - & -0.083 & 0.048 \\
\hline Of transmitting information & $-0.105^{\star}$ & $-0.018^{\star \star}$ & - & $-0.132^{\star}$ & -0.114 \\
\hline \multicolumn{6}{|l|}{ ON STRATEGIC } \\
\hline Of mature & $0.134^{\star *}$ & 0.089 & - & $0.139^{\star \star}$ & 0.050 \\
\hline Of neurotic & 0.055 & -0.009 & - & 0.058 & 0.067 \\
\hline Of Image-distorting & 0.034 & 0.023 & - & 0.040 & 0.017 \\
\hline Of mature & $-0.135^{\star \star}$ & $-0.117^{\star \star}$ & - & $-0.141^{\star}$ & -0.024 \\
\hline Of neurotic & $0.213^{\star \star}$ & 0.080 & - & $0.221^{\star \star}$ & 0.141 \\
\hline Of image-distorting & 0.044 & -0.033 & - & 0.044 & 0.077 \\
\hline Of immature & $0.345^{\star *}$ & $0.271^{\star *}$ & - & $0.347^{\star *}$ & 0.076 \\
\hline Of supporting understanding & $-0.160^{\star *}$ & -0.010 & - & $-0.169^{\star \star}$ & -0.159 \\
\hline Of transmitting information & $0.496^{\star \star}$ & $0.471^{\star \star}$ & - & $0.519^{\star \star}$ & 0.048 \\
\hline \multicolumn{6}{|l|}{ ON GPA } \\
\hline Of mature & $0.160^{\star \star}$ & - & $0.056^{\star \star}$ & $0.077^{\star \star}$ & 0.021 \\
\hline Of neurotic & -0.006 & - & -0.006 & 0.008 & 0.014 \\
\hline Of image-distorting & 0.020 & - & -0.005 & -0.001 & 0.004 \\
\hline
\end{tabular}

${ }^{*} p<0.05,{ }^{* *} p<0.01$ (Bootstrap).

(Chamorro-Premuzic et al., 2007). The use of a constructive type of mastery of internal conflict (that allows more conscious awareness of feelings, ideas and their consequences coming along with higher self-esteem) possibly "supports" students to discover that deep as well as strategic approaches work best in securing good grades.

The weak effect of a neurotic defense style on a surface approach depicted in the model, despite their higher correlation, may indicate that the rearranging of ideas and feelings involved in neurotic defenses is typical especially during this age period due to social and study-related demands (Seaton and Beaumont, 2011), so that students have learned to adjust to a range of teaching-learning situations and to the relevant uneasy feelings by regulating them privately. The effective private regulation of emotions reduces the need for students to employ maladaptive learning activities, a surface approach, to reduce anxiety in order to perform well in the exams. Overall, the model suggested in the present study indicates that defense styles act as an antecedent of approaches that in turn have some impact on achievement. This is in line with (a) the idea of Presage, Process and Product factors in students learning (Biggs and Tang, 2011) indicating defense styles as a presage factor (b) recent studies exploring adaptive and maladaptive behaviors and cognitions contributing to academic control as distal antecedents of learning related emotions (Niculescu et al., 2015) and (c) distal antecedents in the context of contemporary motivation research (Pekrun and GarciaLinnenbrink, 2014; Linnenbrink-Garcia et al., 2016); defense mechanisms, as involuntary coping mechanisms comprising an implicit emotion-regulation construct are likely to contribute to Pekrun's Control-Value model. They can be seen to regulate affect (stress, moods, emotions and impulses) which directs and influences students' behavior. Acting in a constructive-adaptive way or in a maladaptive way involving either the refusal of some aspects of reality (by splitting the image of self and other) 
TABLE 6 | The decomposition of the two significant indirect effects on GPA (from the model of Figure 3), mentioned in Table 5.

\begin{tabular}{|c|c|c|c|c|}
\hline & \multicolumn{3}{|c|}{ Through } & \multirow{2}{*}{$\begin{array}{l}\text { Total indirect effect on } \\
\text { GPA }\end{array}$} \\
\hline & Deep & Strategic & Surface & \\
\hline From mature & 0.023 & 0.024 & 0.009 & 0.056 \\
\hline $\begin{array}{l}\text { From supporting } \\
\text { understanding }\end{array}$ & 0.048 & 0.075 & 0.001 & 0.123 \\
\hline
\end{tabular}

or the employment of provocative actions toward the other, defense mechanisms can be seen to have an impact not only on the quality of learning but also on students achievement: not only are students using mature defense styles more organized, motivated and hard-working but they also approach learning with an intention to comprehend, to engage in active conceptual analysis that it generally results in a deep level of understanding rather than in a surface approach having further an impact on achievement (Asikainen and Gijbels, 2017).

\section{Practical Implications}

Although teaching is not likely to be adjusted to individual differences, it is useful for universities to have an idea of the web of causalities involved in student learning and how defense mechanisms have an effect on the quality of learning and achievement. Institutions invest in students success and quality of learning and promote peer collaboration along with cooperation with tutors; thus those responsible for courses that aim to enhance students engagement with learning would be useful to take into account that students' perceptions of the world and their relations with others are colored by the use of particular defenses that manifest similar social, cognitive and emotional behaviors. Besides, a social difficulty apparent in the use of less mature defenses enhances the possibility for students to walk their own paths than cooperate with others. Moreover, peer-tutoring and peer-counseling could be promoted by our understanding of the relation between psychological maturity and quality of learning; psychologically mature good students could contribute as counselors to their peers assuming their readiness to develop empathy and active listening.

\section{Limitations and Future Research}

The self-report measure used to explore defense mechanisms and the self-reported grades can be seen as main limitations of the study. Most of the DSQ measures remain to be improved (Nicolas et al., 2017a). In particular, the psychometric limitations of the DSQ-40 bring to the fore the need for the improvement of the instrument by the substitution of some of the items. Items from other versions of the DSQ or new items developed by clinicians (or psychoanalytic oriented researchers) could be used for further testing. Subsequently, the weak associations among the variables should be seen through the lens of the psychometric limitations of the DSQ-40. Moreover, no information was collected about students' academic history or their attitudes towards learning and their level of adjustment in order to lend validity to our findings.

Also, the findings should be treated with caution since only students who attended the classes had the opportunity to participate in the study and fill in the printed questionnaires, at a particular time. However, the study seems to add to the increasing literature in the interface of mental health and educational psychology concerning the web of factors that have an effect on learning. From this perspective, future research should address the role of both implicit/nonconscious and explicit/conscious emotion regulation in students' learning along with academic emotions. In the context of student learning research, it would be interesting to get data from students from different subject areas to see how defenses relate to approaches and achievement assuming that more competitive learning environments evoke higher levels of stress (Nicolas et al., 2017b; Lindblom-Ylänne et al., 2018).

\section{CONCLUSIONS}

The study reveals a new research path. It suggests the contribution of defense styles to the SAL tradition and sheds light on the psychometric properties of the DSQ-40. It reveals their role in the construction of adaptive and maladaptive learning patterns along with approaches to learning, preferences for courses and GPA. Besides, it indicates the function of mature, neurotic, image-distorting and immature defense styles as predictors of approaches to learning. Only the mature defense style has an effect on GPA through deep and strategic approach. An indirect effect on GPA of the same nature is also the case for students' preference for courses that support understanding. Associations appear in the expected direction. The findings illuminate our understanding of factors influencing the way students go about learning and broadens our horizon of adaptive and maladaptive elements involved in learning in higher education.

\section{AUTHOR CONTRIBUTIONS}

FM contributed to the statistical analysis of the data-sets and research methodology. EK contributed to the theory of educational psychology in higher education, defense mechanism, emotions and research methodology. VA contributed to the theory of emotions, data collection and the development of the data-sets.

\section{ACKNOWLEDGMENTS}

The study was partially supported by the State Scholarships Foundation of Greece (IKY), under the Erasmus+ Role Models Program (peer counselling in higher education) funded by the European Commission. 


\section{REFERENCES}

Anderson, B., Lee, S., Simpson, M., and Stein, S. (2011). Study orchestrations in distance learning: identifying dissonance and its implications for distance educators. Int. Rev. Res. Open Distance Learn. 12, 1-17 doi: 10.19173/irrodl.v12i5.977

Andrews, G., Pollock, C., and Stewart, G. (1989). The determination of defense style by questionnaire. Arch. Gen. Psychiatry 46, 455-460. doi: 10.1001/archpsyc.1989.01810050069011

Andrews, G., Singh, M., and Bond, M. (1993). The defense style questionnaire. J. Nerv. Ment. Dis. 181, 246-256. doi: 10.1097/00005053-199304000-00006

Asikainen, H., and Gijbels, D. (2017). Do students develop towards more deep approaches to learning during studies? A systematic review on the development of students' deep and surface approaches to learning in higher education. Educ. Psychol. Rev. 29, 205-234. doi: 10.1007/s10648-017-9406-6

Asikainen, H., Parpala, A., Lindblom-Ylänne, S., Vanthournout, G., and Goertjens, L. (2014). The development of approaches to learning and perceptions of the teaching-learning environment during bachelor level studies and their relation to study success. High. Educ. Stud. 4, 24-36. doi: 10.5539/hes.v4 $\mathrm{n} 4 \mathrm{p} 24$

Baeten, M., Kyndt, E., Struyven, K., and Dochy, F. (2010). Using student-centred learning environments to stimulate deep approaches to learning: factors encouraging or discouraging their effectiveness. Educ. Res. Rev. 5, 243-260. doi: 10.1016/j.edurev.2010.06.001

Beaton, D. E., Bundardier, C., Guillemin, F., and Feraz, M. B. (2000). Guidelines of the process of cross-cultural adaptation of self-report measures. Spine 25, 3186-3191. doi: 10.1097/00007632-200012150-00014

Biggs, J. B., and Tang, C. (2011). Teaching for Quality Learning at University, 4th Edn. Buckingham: Open University Press.

Bond, M. P. (1992). "An empirical study of defensive styles: The Defense Style Questionnaire," in Ego Mechanisms of Defense: A Guide for Clinicians and Researchers, ed G. E. Vaillant (Washington, DC: American Psychiatric Press, Inc), $127-158$.

Bond, M. P. (2004). Empirical studies of defense style: relationships with psychopathology and change. Harv. Rev. Psychiatry 12, 263-278. doi: $10.1080 / 10673220490886167$

Bond, M. P., Gardner, S. T., Christian, J., and Sigal, J. (1983). Empirical study of self-rated defense styles. Arch. Gen. Psychiatry 40, 333-338. doi: 10.1001/archpsyc.1983.01790030103013

Bond, M. P., and Vaillant, J. S. (1986). An empirical study of the relationship between diagnosis and defense style. Arch. Gen. Psychiatry 43, 285-288. doi: 10.1001/archpsyc.1986.01800030103012

Burton, L. J., Taylor, J. A., Dowling, D. G., and Lawrence, J. (2009). Learning approaches, personality and concepts of knowledge of first-year students: mature-age versus school leaver. Stud. Learn. Eval. Innov. Dev. 6, 65-81.

Byrne, M., Flood, B., and Willis, P. (2004). Using the student learning framework to explore the variation in academic performance of European business students. J. Further High. Educ. 28, 67-78. doi: 10.1080/0309877032000161823

Campos, R. C., Besser, A., and Blatt, S. J. (2011). The relationships between defenses and experiences of depression: an exploratory study. Psychoanal. Psychol. 28, 196-208. doi: 10.1037/a0022420

Carvalho, A. F., Hyphantis, T. N., Taunay, T. C., Macêdo, D. S., Floros, G. D., Ottoni, G. L., et al. (2013). The relationship between affective temperaments, defensive styles and depressive symptoms in a large sample. J. Affect. Disord. 146, 58-65. doi: 10.1016/j.jad.2012.08.038

Chamorro-Premuzic, T., Furnham, A., and Lewis, M. (2007). Personality and approaches to learning predict preference for different teaching methods. Learn. Individ. Differ. 17, 241-250. doi: 10.1016/j.lindif.2006.12.001

Cramer, P. (2008). Seven pillars of defense mechanism theory. Soc. Pers. Psychol. Comp. 2, 1963-1981. doi: 10.1111/j.1751-9004.2008.00135.x

Cramer, P. (2015a). Understanding defense mechanisms. Psychodyn. Psychiatry 43, 523-552. doi: 10.1521/pdps.2015.43.4.523

Cramer, P. (2015b). Defense mechanisms: 40 years of empirical research. J. Pers. Assess. 97, 114-122. doi: 10.1080/00223891.2014.947997

Cramer, P., and Tracy, A. (2005). The pathway from child personality to adult adjustment: the road is not straight. J. Res. Pers. 39, 369-394. doi: 10.1016/j.jrp.2004.07.003
De la Fuente, J., and Cardelle-Elawar, M. (2009). Research on action-emotion style and study habits: effects of individual differences on learning and academic performance of undergraduate students. Learn. Individ. Diff. 19, 567-576. doi: 10.1016/j.lindif.2009.07.009

De la Fuente, J., Fernández-Cabezas, M., Cambil, M., Vera, M. M., GonzálezTorres, M. C., and Artuch-Garde, R. (2017). Linear relationship between resilience, learning approaches, and coping strategies to predict achievement in undergraduate students. Front. Psychol. 8:1039. doi: 10.3389/fpsyg.2017. 01039

De la Fuente, J., Zapata, L., and Martínez-Vicente, J. M. (2016). "Effects of level of personal self-regulation and different contexts of stress on coping strategies," in Academic Performance: Student Expectations, Environmental Factors and Impacts on Health, ed C. H. Gallagher (New York, NY: Nova Publisher), $77-90$.

Dickinson, E., and Adelson, J. (2016). Choosing among multiple achievement measures: applying multi0trait-multimethod confirmatory factor analysis to state assessment ACT, and student GPA data. J. Adv. Acad. 27, 4-22. doi: $10.1177 / 1932202 X 15621905$

Diseth, A. (2001). Validation of a Norwegian version of the approaches and study skills inventory for students (ASSIST): application of structural equation modeling. Scand. J. Educ. Res. 45, 381-394. doi: 10.1080/00313830120096789

Diseth, Å., Pallesen, S., Brunborg, G., and Larsen, S. (2010). Academic achievement among first semester undergraduate psychology students: the role of course experience, effort, motives and learning strategies. High. Educ. 59, 335-352. doi: 10.1007/s10734-009-9251-8

Duff, A. (2003). Quality of learning on an MBA programme: the impact of approaches to learning in academic performance. Educ. Psychol. 23, 127-139. doi: 10.1080/01443410303230

Duff, A., Boyle, E., Dunleavy, K., and Ferguson, J. (2004). The relationship between personality, approach to learning and academic performance. Pers. Individ. Dif. 36, 1907-1920. doi: 10.1016/j.paid.2003.08.020

Entwistle, N., Karagiannopoulou, E., Olafsdottir, A., and Walker, P. (2015). "Research into student learning and university teaching," in Researching Higher Education: International Perspectives on Theory, Policy and Practice, eds M. Case and J. Huisman (Routledge).

Entwistle, N., and McCune, V. (2013). The disposition to understand for oneself at university: Integrating learning processes with motivation and metacognition. Br. J. Educ. Psychol. 83, 267-279. doi: 10.1111/bjep. 12010

Entwistle, N., McCune, V., and Walker, P. (2001). "Conceptions, styles, and approaches within higher education: Analytical abstractions and everyday experience," in Perspectives on Thinking, Learning and Cognitive Styles, ed R. J. Sternberg and L. F. Zhang (Mahwah, NJ: Lawrence Erlbaum Associates), 103-136.

Entwistle, N. J. (2009). Teaching for understanding at university: Deep approaches and distinctive ways of thinking. Basingstoke: PalgraveMacmillan.

Entwistle, N. J. (2018). Student Learning and Academic Understanding: A Research Perspective and Implications for Teaching. New York, NY; Oxford: Elsevier.

Entwistle, N. J., and Ramsden, P. (1983). Understanding Student learning. London: Croom Helm.

Freud, A. (1966). The Ego and the Mechanisms of Defense. New York, NY: International University Press.

Furnham, A., and Chamorro-Premuzic, T. (2005).Individual differences and beliefs concerning preference for university assessment methods. J. Appl. Soc. Psychol. 35, 1968-1994. doi: 10.1111/j.1559-1816.2005.tb02205.x

Furnham, A., Nuygards, S., and Chamorro-Premuzic, T. (2013). Personality, assessment methods and academic performance. Instr. Sci. 41, 975-987. doi: 10.1007/s11251-012-9259-9

Gefen, D., Straub, D., and Boudreau, M. C. (2000). Structural equation modeling and regression: guidelines for research practice. Commun. Assoc. Inform. Syst. $4,1-77$.

Gijbels, D., Donche, V., Richardson, J., and Vermunt, J. (2013). Learning Patterns in Higher Education: Dimensions and Research Perspectives. New York, NY: Routledge.

Giovazolias, T., Karagiannopoulou, E., and Mitsopoulou, E. (2017). Can the factor structure of the Defense Style Questionnaire (DSQ-40) contribute to our understanding of parental acceptance/rejection, bullying, victimization and 
perceived well-being in Greek early adolescents? Eur. J. Psychol. 13, 269-285. doi: 10.5964/ejop.v13i2.1090

Haarala-Muhonen, A., Ruohoniemi, M., Parpala, A., Komulainen, E., and Lindblom-Ylänne, S. (2017). How do the different study profiles of first-year students predict their study success, study progress and the completion of degrees? High. Educ. 74, 949-962. doi: 10.1007/s10734-016-0087-8

Hagenauer, G., and Volet, S. (2014). Teacher-student relationship at university: an important yet under-researched field. Oxf. Rev. Educ. 40, 370-388. doi: 10.1080/03054985.2014.921613

Hambleton, R. K. (2001). The next generation of the ITC test translation and adaptation guidelines. Eur. J. Psychol. Assess. 17, 164-172. doi: 10.1027//1015-5759.17.3.164

Herrmann, K. J., McCune, V., and Bager-Elsborg, A. (2017). Approaches to learning as predictors of academic achievement: results from a large scale, multi-level analysis. Högre utbildning 7, 29-42. doi: 10.23865/hu.v7.905

Hyphantis, T. (2010). The Greek version of the Defense Style Questionnaire: psychometric properties in three different samples. Compr. Psychiatry 51, 618-629. doi: 10.1016/j.comppsych.2010.03.005

Kahn, J. H. (2006). Factor analysis in counseling psychology research, training, and practice: principles, advances, and applications. Couns. Psychol. 34, 684-718. doi: $10.1177 / 0011000006286347$

Karagiannopoulou, E., Athanasopoulos, V., and Hyphantis, T. H. (2015). "Exploring associations between students' defense styles and approaches to learning," in Paper Presented at the Biannual EARLI Conference (Limassol, Cyprus), 25-29.

Karagiannopoulou, E., and Christodoulides, P. (2009). "The Approaches and Study Skills Inventory for Students: Reliability and validity in a Greek university student sample," in Scientific Annals of the Psychological Society of Northern Greece, Studies on Psychological Assessment, Vol. 7, ed A. Brouzos and P. Misailides, (Athens: Ellinika Grammata), 217-243.

Karagiannopoulou, E., and Entwistle, N. (2013). Influences on personal understanding: approaches to learning, perceptions of assessment, and the "meeting of minds". Psychol. Teaching Rev. 13, 80-96.

Karagiannopoulou, E., and Milienos, F. S. (2013). Exploring the relationship between experienced students' preference for open and closed-book examinations, approaches to learning and achievement. Educ. Res. Eval. 19, 271-296. doi: 10.1080/13803611.2013.765691

Karagiannopoulou, E., and Milienos, F. S. (2015). Testing two path models to explain relationships between experiences of the learning environment, approaches to learning and achievement. Educ. Psychol. 35, 26-52. doi: 10.1080/01443410.2014.895800

Kember, D., Leung, D., and McNaught, C. (2008). A workshop activity to demonstrate that approaches to learning are influenced by the teaching and learning environment. Active Learn. High. Educ. 9, 43-56. doi: $10.1177 / 1469787407086745$

Kramer, U. (2010). Coping and defense mechanisms: what's the difference? Second act. Psychol. Psychother. 83, 207-221. doi: 10.1348/147608309X475989

Kuncel, N., Crebe, M., and Thomas, L. (2005). The validity of self reported grade point averages, class ranks and test scores: a meta-analysis and review of the literature. Rev. Educ. Res. 75, 63-82. doi: 10.3102/00346543075 001063

Kyndt, E., Donche, V., Coertjens, L., van Daal, T., Gijbels, D., and Van Petegem, P. (2018). Does self-efficacy contribute to the development of students' motivation across the transition from secondary to higher education? Eur. J. Psychol. Educ. doi: 10.1007/s10212-018-0389-6. [Epub ahead of print].

Laczkovics, C., Fonzo, G., Bendixsen, B., Shpigel, E., Lee, I., Skala, K., et al. (2018). Defense mechanism is predicted by attachment and mediates the maladaptive influence of insecure attachment on adolescent mental health. Curr. Psychol. doi: 10.1007/s12144-018-9839-1. [Epub ahead of print].

Lindblom-Ylänne, S. (2003). Broadening an understanding of the phenomenon of dissonance. Stud. High. Educ. 28, 63-77. doi: 10.1080/03075070309306

Lindblom-Ylänne, S., Parpala, A., and Postareff, L. (2018). What constitutes the surface approach to learning in the light of new empirical evidence? Stud. High. Educ. doi: 10.1080/03075079.2018.1482267. [Epub ahead of print].

Lindblom-Ylänne, S., Saariaho, E., Inkinen, M., Haarala-Muhonen, A., and Hailikari, T. (2015). Academic procrastinators, strategic delayers and something betwixt and between: an interview study. Frontline Learn. Res. 3, 47-62. doi: $10.14786 /$ flr.v3i2.154
Linnenbrink-Garcia, L., Patall, E. A., and Pekrun, R. (2016). Adaptive motivation and emotion in education: research and principles for instructional design. Policy Insights Behav. Brain Sci. 3, 228-236. doi: 10.1177/2372732216 644450

Martin, A. J. (2007). Examining a multidimensional model of student motivation and engagement using a construct validation approach. Br. J. Educ. Psychol. 77, 413-440.doi: 10.1348/000709906X118036

Marton, F. (1975). "What does it take to learn?," in How Students Learn, eds N. J. Entwistle and D. Hounsell (Lancaster: Institute for post-compulsory education), 125-138. (For an extended version see N. J. Entwistle (ed.). (1976). Strategies for Research and Development in Higher Education (Amsterdam: Swets\&Zeitlinger/Council of Europe).

Marton, F., Hounsell, D. J., and Entwistle, N. J. (1984). The Experience of Learning, 2nd Edn. Edinburgh: Scottish Academic Press.

Marton, F., and Säljö, R. (1976). On qualitative differences in learning: I-outcome and process. Br. J. Educ. Psychol. 46, 4-11. doi: 10.1111/j.2044-8279.1976.tb02980.x

McDonald, R. P. (1999). Test Theory: A Unified Treatment. Mahwah, NJ: Lawrence Erlbaum Associates.

Nicolas, M., Martinent, G., Drapeau, M., Chahraoui,. K.,Vacher, P., and deRoten, Y. (2017b). Defense profiles in adaptation process to sport competition and their relationships with coping, stress and control. Front. Psychol. 8:2222.doi: 10.3389/fpsyg.2017.02222

Nicolas, M., Martinent, G., Drapeau, M., and deRoten, Y. (2017a). Development and evaluation of the psychometric properties of the Short Defense Style Questionnaire (DSQ-26). Int. J. Psychol. Psychol. Ther. 17, 175-187.

Niculescu, A. C., Tempelaar, D., Dailey-Hebert, A., Segers, M., and Gijselaers, W. (2015).Exploring the antecedents of learning-related emotions and their relations with achievement outcomes. Frontline Learn. Res. 3, 1-17. doi: $10.14786 / f l r . v \% 25 v i \% 25 i .136$

Öhrstedt, M., and Lindfors, P. (2018). Linkages between approaches to learning, perceived stress and expected and actual academic outcomes among firstsemester psychology students. J. Further High. Educ. 42, 116-129.

Pekrun, R., and Garcia-Linnenbrink, L. (2014). International Handbook of Emotions in education. New York, NY: Routledge.

Postareff, L., Lindblom-Ylänne, S., and Parpala, A. (2014). Explaining university students' strong commitment to understand through individual and contextual elements. Frontline Learn. Res. 2, 31-49. doi: 10.14786/flr.v2i1.63

Postareff, L., Mattsson, M., Lindblom-Ylänne, S., and Hailikari, T. (2017). The complex relationship between emotions, approaches to learning, study success and study progress during the transition to university. High. Educ. 73, 441-457. doi: 10.1007/s10734-016-0096-7

Postareff, L., Parpala, A., and Lindblom-Ylänne, S. (2015). Factors contributing to changes in a deep approach to learning in different learning environments. Learn. Environ. Res. 18, 315-333.

Putwain, D., Sander, P., and Larkin, D. (2013). Academic self-efficacy in study-related skills and behaviours: relations with learning-related emotions and academic success. Br. J. Educ. Psychol. 83, 633-650. doi: $10.1111 / j .2044-8279.2012 .02084 . x$

Rice, T. R., and Hoffman, L. (2014). Defense mechanisms and implicit emotion regulation: a comparison of a psychodynamic construct with one from contemporary neuroscience. J. Am. Psychoanal. Assoc. 62, 693-708. doi: $10.1177 / 0003065114546746$

Richardson, J. T. (2006). Investigating the relationship between variations in students' perceptions of their academic environment and variations in study behaviour in distance education. Br. J. Educ. Psychol. 76, 867-893. doi: 10.1348/000709905X69690

Richardson, M., Abraham, C., and Bond, R. (2012). Psychological correlates of university students' academic performance: a systematic review and metaanalysis. Psychol. Bull. 138, 353-387. doi: 10.1037/a0026838

Robinson, A., Ranellucci, J., Lee, K., Wormington, V., Roseth, J., and LinnenbrinkGarcia, L. (2017). Affective profiles and academic success in a college science course. Contemporary Educ. Psychol. doi: 10.1016/j.cedpsych.2017.08.004

Rowe, A., Fitness, J., and Wood, L. (2015). University student and lecturer perceptions of positive emotions in learning. Int. J. Qual. Stud. Educ. 28, 1-2. doi: 10.1080/09518398.2013.847506

Ruuttu, T., Pelkonen, M., Holi, M., Karlsson, L., Kiviruusu, O., Heila, H., et al. (2006). Psychometric properties of the Defense Style 
Questionnaire (DSQ-40) in adolescents. J. Nerv. Ment. Dis. 194, 98-105. doi: 10.1097/01.nmd.0000198141.88926.2e

Rytkönen, H., Parpala, A., Lindblom-Ylänne, S., Virtanen, V., and Postareff, L. (2012). Factors affecting bioscience students' academic achievement. Instr. Sci. 40, 241-256. doi: 10.1007/s11251-011-9176-3

Sala, M., Testa, S., Pans, F., and Molina, P. (2015). Emotion regulation and defense mechanisms. J. Individ. Diff. 36, 19-29. doi: 10.1027/1614-0001/a000151

Sandover, D., Lonas-Dwyer, D., and Marr, T. (2015). Graduate entry and undergraduate medical students' study approaches, stress levels and ways of coping: a five year longitudinal study. BMC Med. Educ. 15:5. doi: 10.1186/s12909-015-0284-7

Schauenburg, H., Willenborg, V., Sammet, I., and Ehrenthal, J. (2007). Selfreported defense mechanisms as an outcome measure in psychotherapy: a study on the German version of the Defense Style Questionnaire DSQ 4. Psychol. Psychother. 8, 355-366. doi: 10.1348/147608306X146068

Seaton, C. L., and Beaumont, S. L. (2011). Identity processing styles and defense styles during emerging adulthood: implications for life distress. Identity Int. J. Theory Res. 11, 1-24. doi: 10.1080/15283488.2011.540736

Spinhoven, P., van Gaalen, H. A. E., and Abraham, R. E. (1995). The defense style questionnaire: apsychometricexamination. J. Pers. Disord. 9, 124-133. doi: 10.1521/pedi.1995.9.2.124

Thygesen, K. L., Drapeau, M., Trijsburg, R. W., Lecours, S., and de Roten, Y. (2008).Assessing defense styles: factor structure and psychometric properties of the new Defense Style Questionnaire 60 (DSQ-60). Int. J. Psychol. Psychol. Ther. 8, 171-181.

Trigwell, K., Ellis, R. A., and Han, F. (2012). Relations between students' approaches to learning, experienced emotions and outcomes of learning. Stud. High. Educ. 37, 811-824. doi: 10.1080/03075079.2010.549220

Trigwell, K., and Prosser, M. (1991).Improving the quality of student learning: the influence of learning context and student approaches to learning on learning outcomes. High. Educ. 22, 251-266. doi: 10.1007/BF00132290

Vaillant, G. E. (1977). Adaptation to Life. Boston, MA: Little Brown.

Vaillant, G. E. (2011). Involuntary coping mechanisms: a psychodynamic perspective. Dialogues Clin. Neurosci. 13, 366-370.
Valadas, S. C., Gonçalves, F., and Faísca, L. (2010). Approaches to studying in higher education Portuguese students: a Portuguese version of the approaches and study skills inventory for students. High. Educ. 59, 259-275. doi: 10.1007/s10734-0099246-5

Von Stumm, S., and Furnham, A. (2012). Learning approaches: associations with typical intellectual engagement, intelligence and the big five. Pers. Individ. Diff. 53, 720-723. doi: 10.1016/j.paid.2012. 05.014

Wagerman, A., and Funder, D. (2007). Acquaintance reports of personality and academic achievement: a case for conscientiousness. J. Res. Pers. 41, 221-229. doi: 10.1016/j.jrp.2006.03.001

Watson, D. C. (2002). Predicting psychiatric symptomatology with the Defense Style Questionnaire-4. Int. J. Stress Manage. 9, 275-287. doi: 10.1023/A:1019930332257

Wilkinson, W., and Ritchie, T. (2015). The dimensionality of Defense Mechanism parcels in the Defense Style Questionnaire-4. Psychol. Assess. 27, 326-331. doi: $10.1037 /$ pas0000051

Zhang, L. F. (2015). Defense mechanisms and thinking styles. J. Cogn. Educ. Psychol. 14, 163-179. doi: 10.1891/1945-8959.14.2.163

Zhang, L. F., and Sternberg, R. J. (2006). The Nature of Intellectual Styles. Mahwah, NJ: Lawrence Erlbaum Associates.

Conflict of Interest Statement: The authors declare that the research was conducted in the absence of any commercial or financial relationships that could be construed as a potential conflict of interest.

Copyright (C) 2018 Karagiannopoulou, Milienos and Athanasopoulos. This is an open-access article distributed under the terms of the Creative Commons Attribution License (CC BY). The use, distribution or reproduction in other forums is permitted, provided the original author(s) and the copyright owner(s) are credited and that the original publication in this journal is cited, in accordance with accepted academic practice. No use, distribution or reproduction is permitted which does not comply with these terms. 